\title{
CUBANOS Y ESPAÑOLES DESPUÉS DEL 98: DE LA CONFRONTACIÓN A LA CONVIVENCIA PACÍFICA ${ }^{1}$
}

\author{
POR \\ ALEJANDRO GARCÍA ÁLVAREZ \\ Facultad de Filosofía e Historia, Universidad de La Habana
}

CONSUELO NARANJO OROVIO

Centro de Estudios Históricos, C.S.I.C.

\begin{abstract}
Una vez consensuado el sistema de relaciones entre España y Cuba el reajuste de las interacciones entre españoles y cubanos, en el plano concreto de la convivencia, se hizo más fluido, por transitar desde una situación de agudo enfrentamiento representado por la guerra, hasta una convivencia pacífica garantizada por el marco jurídico ofrecido por la república, reforzada por el incremento de la inmigración española, y conservada por el enorme peso de la tradición hispano-cubana.
\end{abstract}

Con la firma del protocolo que puso fin a las hostilidades entre España y Estados Unidos, el 12 de agosto de 1898, se abrió para Cuba un período de paz y reajuste de la sociedad cubana a las condiciones que finalmente fueron establecidas por el Tratado de París. La confrontación entre los cubanos y el sistema de dominación colonial implantado por España en la isla se había caracterizado durante más de treinta años por el enfrentamiento bélico. En el mismo habían tomado partido directa o indirectamente tanto los cubanos como los españoles residentes en la colonia, además de las fuerzas militares enviadas con el fin de sofocar la insurgencia. El fin de la

Sigla UTILIZADA:

AHMAEE, Archivo Histórico del Ministerio de Asuntos Exteriores (Madrid).

1 Trabajo realizado dentro del Proyecto de Investigación PB96-0868 (DGES) 
guerra en Cuba, decidido finalmente por la intervención de la armada y las tropas norteamericanas en el conflicto, introdujo una radical modificación en la situación interna del país, que pasó de un estado de guerra generalizado, a una paz garantizada por fuerzas extranjeras de ocupación.

La paz iniciada en Cuba después del 98 se prolongó de forma ininterrumpida durante todo el tiempo en que permanecieron las tropas de Estados Unidos (1898-1902) y se extendió a los cuatro años en que tuvo lugar la primera administración propia que rigió los destinos de la nación cubana (1902-1906). La elección de la vía armada como medio de oposición política a la reelección del presidente D. Tomás Estrada Palma introdujo la guerra nuevamente en el país en 1906 y, como consecuencia de ello, se inició otro período de intervención militar de Estados Unidos, apenas transcurridos cuatro años desde la instauración de la república. Los hechos políticos enmarcados entre el fin de la Guerra de Independencia y la guerra civil de agosto de aquel año han sido tratados detalladamente y de forma variada por la historiografía cubana ${ }^{2}$. Sin embargo, es preciso incorporar al conocimiento sobre aquellos años algunas apreciaciones acerca de las circunstancias que rodearon el proceso de adaptación de la sociedad cubana a las condiciones de paz, teniendo en cuenta que se trataba sobre todo de una sociedad que había estado agobiada hasta la víspera por una confrontación de vida o muerte con respecto a la independencia de la isla, en la que subyacían además otras contradicciones, tales como las clasistas y las raciales, que, durante los años que duró la lucha, se habían mantenido en un segundo plano hasta el momento en que se alcanzó la separación de España ${ }^{3}$.

\footnotetext{
2 En este sentido, son clásicas las obras de Enrique Collazo, Cuba Intervenida, La Habana, Imprenta Cubana, 1910 y Cuba Independiente, La Habana, Editorial Santiago, Santiago de Cuba, 1981 y especialmente la de Rafael MARTínez ORTIZ, Cuba, los primeros años de la Independencia, publicada en París por Le Libre Livre, en 1929. Más recientemente se han publicado algunos trabajos críticos sobre la época, véanse Miriam FERNÁNDEZ, "Construyendo la nación. Proyectos e ideologías en Cuba, 1899-1909" y Michael ZEUSKE, "1898. Cuba y el problema de la "transición pactada». Prolegómenos a una historia de la cultura política en Cuba (1880-1920)", publicados ambos trabajos en Consuelo NARANJO, Miguel Angel PUIGSAMPER y Luis M. GARCía (eds.), La nación soñada: Cuba, Puerto Rico y Filipinas ante el 98, Aranjuez-Madrid, Ediciones Doce Calles, 1996, pp. 123-130 y 131-148.

3 En los últimos años las relaciones raciales y el papel desempeñado por la "raza" en la conformación social y cultural de Cuba han venido a ocupar un lugar central en algunos estudios sobre el siglo XX. Véanse los trabajos de Aline Helg, Our Rightful Share. The Afro-Cuban Struggle for Equality, 1886-1912, North Carolina, 1995; Michael ZEUSKE "El
}

\section{R. I., $1998, \mathrm{n}^{\circ} 212$}


Es a partir de estas consideraciones que el presente trabajo se propone como objetivo la identificación de algunos elementos de interés que permitan caracterizar el escenario de paz en que la sociedad cubana debió desenvolverse después del 98. Se trata sobre todo, de registrar los matices contradictorios que se manifestaron en las relaciones entre los sectores cubano y español de la población insular, como una secuela resultante de la situación colonial y, sobre todo, de los largos años de confrontación precedentes.

Una visión de conjunto de los acontecimientos correspondientes al período de tiempo seleccionado puede arrojar como resultado que el primer ensayo de república independiente, que tuvo lugar en Cuba entre 1902 y 1906, constituyó una experiencia fracasada que terminó del mismo modo que comenzó: con una intervención militar de Estados Unidos. Este período sirvió como evidencia de que algo no había funcionado bien en el experimento de construcción republicana. A partir de esta premisa, conviene a los objetivos del presente trabajo la delimitación de algunas cuestiones de especial interés histórico.

La mayor parte de la historiografía cubana ha coincidido en afirmar que la contradicción fundamental existente en la Cuba de la última década del siglo XIX fue la ya histórica confrontación entre el independentismo radical del pueblo cubano y la dominación colonial, defendida a sangre y fuego por la corona española y los políticos de la metrópoli. La respuesta de una parte importante de la población insular a tales posiciones había sido, desde 1868, la lucha armada en favor de la obtención de un objetivo único representado por la independencia absoluta. No es superfluo el hecho de que se señale con reiteración la existencia de una autoconciencia de nación en Cuba, no sólo desde el inicio de la Guerra de los Diez Años, sino desde mucho antes, quizás desde finales del siglo XVIII con la

\footnotetext{
poder discreto de los ex-esclavos: "raza", clientelas y poder nacional en Cuba 1895-1908", ponencia presentada en el XI Congreso Internacional de AHILA, Liverpool, 17-22 de septiembre, 1996; Rebecca ScotT, "Relaciones de clase e ideologías raciales: acción rural colectiva en Louisiana y Cuba, 1865-1912", Historia Social, núm. 22, 1995, pp. 127-149; Ada FERRER "Esclavitud, ciudadanía y los límites de la nacionalidad cubana: la guerra de los diez años, 1868-1878", Historia Social, núm. 22, 1995, pp. 101-126, y Consuelo Naranjo Orovio y Armando García GonZÁlez, Racismo e inmigración en Cuba en el siglo XIX, Madrid-Aranjuez, Ediciones Doce Calles-FIM, 1996.
} 
adopción del pensamiento económico liberal por parte de los grupos oligárquicos ilustrados de la isla 4 .

No obstante la anterior afirmación, es difícil demostrar en qué medida había existido, al margen de los grupos dirigentes de la revolución cubana de 1895 , entre la población de la isla de finales del siglo XIX una idea clara de la república que se aspiraba fundar una vez alcanzada la independencia, a pesar de los lineamientos que en tal dirección formulara José Martí como líder indiscutible de la lucha independentista durante aquella etapa. La subordinación de todo interés al objetivo fundamental que era la independencia y la postergación de cualquier otro propósito para el futuro, dejó en suspenso la definición del proyecto republicano más allá de ideas y metáforas cuya exégesis debieron hacer otros hombres en épocas posteriores. Las ideas y la actividad de José Martí, centradas en el ideal independentista, concibieron la unidad para la lucha como un catalizador de conciencias que podría servir como vehículo idóneo para la fundación de una república "con todos y para el bien de todos", colocada por encima de los intereses de clases, las diferencias raciales y los diversos orígenes nacionales de la población de $\mathrm{Cuba}^{5}$.

Sin embargo, la sociedad cubana de finales del siglo XIX, a pesar de contar con un esclarecido ideario independentista y una sólida tradición heroica acumulada por largos años de lucha, contenía elementos de dispersión a causa de la propia composición interna de su población, de su prolongada situación colonial y también por las características de su metrópoli.

Cuba había sido sobre todo y durante cuatro siglos una colonia de España. Los sectores del ejército, marina, hacienda y ultramar habían constituido en la Cuba colonial espacios fundamentales para dar empleo a la burocracia española y, por consiguiente, formaron parte del entramado de compromisos y clientelas de los políticos de la metrópoli, sin contar con el hecho de que los cargos fuera del territorio peninsular gozaron de primas ventajosas y la posibilidad de ac-

\footnotetext{
4 Sergio Aguirre, Eco de Caminos, La Habana, Editorial de Ciencias Sociales, 1974, pp. 401-418. Julio LE RIVEREND, Historia económica de Cuba, La Habana, Editora Universitaria, 1971, pp. 274-288 y Josef OPATRNY, "Algunos aspectos de la formación de la nación cubana", C. NARANJo y T. MAllo (eds.), Cuba, la Perla de las Antillas, Aranjuez-Madrid, Ediciones Doce Calles-C.S.I.C., 1994, pp. 249-259, abordan aspectos de esta cuestión.

5 Jorge IBARRA, José Martí, dirigente político e ideólogo revolucionario, La Habana, Editorial de Ciencias Sociales, 1980, pp. 232-233.
}

\section{R.I., $1998, \mathrm{n}^{\circ} 212$}


ceder a negocios colaterales que podían constituir fuentes de acumulación individual de capitales. Por otra parte, las erogaciones de las cajas insulares bajo el concepto de "clases pasivas" garantizaron con frecuencia una remuneración vitalicia a quienes hubieran prestado servicios en la colonia. Éstas y otras lacras de tipo económico, derivadas de la relación colonial, desaparecieron con la independencia $^{6}$. Libre de tales lastres, la nación cubana emergió al concluir el siglo sometida al tutelaje de su principal socio mercantil, Estados Unidos, y al interés de los grupos empresariales atentos en las capacidades y posibilidades que podía ofrecer su territorio nacional para el desarrollo de una economía complementaria de la norteamericana.

Lograda la pacificación de Cuba y establecidas las reglas del protectorado, no sólo subsistieron otras contradicciones de importancia inherentes a la composición diversa de la sociedad cubana, sino que se manifestaron con mayor libertad y diferentes grados de intensidad. En este sentido, puede hablarse con propiedad de la agudización de contradicciones, como las de clase y las raciales que se habían mantenido latentes en el seno de la sociedad cubana sin posibilidades de ser resueltas durante los años de lucha. Cuestiones de medular interés como son las contradicciones entre diferentes grupos y sectores sociales, en los que el color de la piel siguió desempeñando un papel destacado, así como los procesos de adaptación de entidades de origen colonial a una nueva realidad, llenaron de vigor y de matices el tránsito de la colonia a la república, contribuyendo con ello a la definición de sus perfiles futuros ${ }^{7}$.

\section{DE LA CONFRONTACIÓN A LA CONVIVENCIA PACÍFICA.}

El proceso de paz se inició en Cuba en medio de una verdadera situación de crisis económica. La fundamental industria del país, la azucarera, precisamente a causa de la ubicación rural de sus instalaciones agroindustriales, había resultado gravemente dañada por las

\footnotetext{
6 La política comercial española a finales del siglo XIX ha sido analizada por Inés Roldén, La Unión Constitucional y la política colonial de España en Cuba (1868-1898), Madrid, Universidad Complutense, 1991.

7 Raquel MENDIETA, Cultura. Lucha de clases y conflicto racial, 1878-1895, La Habana, Editorial Pueblo y Educación, 1989.
} 
operaciones militares ${ }^{8}$. Pero los daños generales que sufrió dicha industria no fueron motivados sólo por los efectos destructivos de la guerra sobre las plantaciones e ingenios, sino también por las condiciones negativas que prevalecieron en los mercados azucareros desde el punto de vista del descenso continuo de los precios y por el hecho de que el gobierno norteamericano hubiera mantenido un régimen de derechos plenos al azúcar cubano hasta tanto no se firmara un tratado de reciprocidad con Cuba. Estas circunstancias, prevalecientes hasta la firma del Tratado de Reciprocidad en 1903, obligaron tanto a los productores de azúcar asentados en Cuba como a los nuevos inversionistas, a realizar verdaderos esfuerzos para poner en produción nuevamente las plantaciones, reactivar la infraestructura industrial, asumir pérdidas y dar cumplimiento a los compromisos adquiridos con entidades financieras y mercantiles de Cuba y el extranjero.

Esta situación coyuntural de retroceso productivo y de ruina fue la causa principal de que el problema del empleo revistiera una especial agudeza para las masas desposeídas durante los primeros años de paz. La escasez de medios de subsistencia que siguió a la guerra afectó por igual a cubanos y españoles que se encontraban en Cuba. Las condiciones específicas del país en aquel momento han sido descritas en detalle por los informes del gobierno militar norteamericano en la isla y a través del testimonio de algunos historiadores contemporáneos a los hechos 9 . La penuria afectó también a los soldados españoles, aunque éstos fueron en su mayoría repatriados. Sin embargo, algunos de los que habiendo creado familia en la isla y que sólo podían disponer de un pasaje de regreso en la Trasatlántica Española para volver a España, se vieron en situaciones de casi imposible solución a escala individual. Muchos otros, por lo regular civiles, permanecieron merodeando en parques y plazas, al encontrar-

\footnotetext{
8 Manuel Moreno Fraginals y Manuel MoREno MASÓ, Guerra, migración y muerte, Oviedo, Ediciones Jucar, 1993, pp. 133-134, minimizan la importancia que tuvo la Guerra de Independencia en la destrucción de la industria azucarera cubana, fijando la cifra de 180 centrales como productores activos antes de 1895. Fé IGLESIAS, en un exhaustivo trabajo en proceso editorial titulado Del ingenio al central, ofrece la cifra de 425 ingenios y centrales para 1895 y describe algunas particularidades sobre los efectos destructivos de la guerra sobre dichas instalaciones industriales.

9 John C. BRooke, Civil Report of John C. Brooke, Washington, 1899 y obra de MARTÍNEZ ORTIZ [2].
}

R. I., $1998, \mathrm{n}^{\circ} 212$ 
se la mayor parte de los ingenios todavía paralizados por falta de materias primas o de reparaciones. Estos desposeídos de siempre vieron de repente agravada su situación, al convertirse en extranjeros de la noche a la mañana, deambulando de un sitio a otro, y pidiendo al representante de España en Cuba su repatriación en la condición de indigentes ${ }^{10}$. En general, aquellos españoles de menos recursos, tanto inmigrantes como soldados, reclamaron reiteradamente de sus cónsules el favor de ser trasladados a La Habana con el fin de ser devueltos a la patria. En el caso particular de los ex-combatientes, era conocido que éstos carecían del dinero necesario para el pago del pasaje desde las localidades en que se encontraban hasta los puertos de embarque, pudiendo contar en su lugar sólo con los abonarés y cartas de pago expedidos por la administración española o, en su caso, por las oficinas militares. En estas condiciones de indefensión solían convertirse en presa fácil de los especuladores sin escrúpulos que adquirían dichos documentos a precios fijados generalmente en proporción directa a la urgencia de cada caso ${ }^{11}$. Como un factor de agravamiento de esta situación, se abrió paso una norma no escrita sobre la imposición de restricciones para el acceso de los españoles a los trabajos públicos, donde comenzaron a ser discriminados por su procedencia nacional. Alarmado por el estado de estos grupos deambulantes, el cónsul español en La Habana se vio impelido a reiterar comunicaciones al ministerio de Estado de España, en las cuales se exponía la realidad del momento en los términos siguientes: "Muchos militares, empleados civiles, viudas, españoles todas clases miseria espantosa, piden repatriación. Ruego V.E. por caridad patriotismo se les conceda pasaje plazo prudencial. Sagrario"12.

Por otra parte, la situación de los combatientes del ejército libertador resultó particularmente lastimosa, no sólo a causa del desabastecimiento generalizado y la carencia de fuentes de empleo, sino

10 Carta del cónsul general de España en Cuba, Felipe Sagrario al ministerio de Estado español, La Habana, 20 de septiembre de 1899. AHMAEE. Leg. 1905, Exp. 1899 (Correspondencia Consular, Habana, 1899-1900).

11 Carta del cónsul de España en Cienfuegos Eduardo Álvarez, al cónsul general de España en Cuba, Cienfuegos, agosto de 1898. AHMAEE, Leg. H-1872 (Correspondencia Consular, Cienfuegos, 1898-1911).

12 Telegrama del cónsul general de España en Cuba al ministro de Estado español, La Habana, 20 de septiembre de 1899. AHMAEE. Leg. 1905, Exp. 1899 (Correspondencia Consular, Habana, 1899-1900). 
por su especial y contradictoria situación de ejército vencedor en la guerra y a la vez vencido por una pacificación que, sin embargo, les obligó a mantenerse sobre las armas después de la guerra. A lo largo de varios meses las tropas cubanas todavía permanecieron en campamentos alejados de las ciudades hasta tanto pudieran recibir alguna ayuda económica y la orden de desmovilización emanada de la autoridad cubana correspondiente. Es probable que el gobierno interventor tuviera la intención de esperar que la presión del hambre pudiera finalmente rendir la actitud de los oficiales y tropas del ejército libertador que se mantenían en campaña y facilitar con ello su desmovilización sin costo adicional alguno. Sin embargo, la actitud asumida por el general Máximo Gómez favoreció la materialización de este hecho de modo un tanto precario, a partir de la aceptación de un donativo norteamericano de tres millones de dólares, hasta que posteriormente, ya en la república, se lograra otra fórmula de compensación mediante un empréstito con la banca extranjera.

La pacificación de Cuba se inició una vez firmada la paz entre Estados Unidos y España, con el desplazamiento inmediato del ejército español desde sus cuarteles y fortalezas, seguido de la ocupación de los mismos por el ejército norteamericano. A ello también se unió la creación de sus propios campamentos, como el de Columbia en la ciudad de La Habana y otros en el interior del país. No obstante la sustitución rápida y total de la fuerza militar española acantonada en Cuba, una parte sustancial de la vieja administración pública se mantuvo por el momento en sus puestos, con el claro objetivo de mantener algunas instituciones que permitieran el tránsito a la república y la constitución de un estado nacional.

La sustitución del personal empleado en estas esferas se hizo de manera gradual, dejando espacios que en principio debieron ser cubiertos por aspirantes cubanos presuntamente vinculados al movimiento independentista, o manifiestamente simpatizantes del mismo. La aspiración a ocupar cargos públicos en la nueva administración pareció ser, por el momento, una de las pocas opciones que quedaron a los cubanos nativos para sobrevivir en aquella situación. Por esta razón, dicho asunto se convirtió en foco de conflicto a causa de la insatisfacción que solía generar la selección de los funcionarios y empleados que debían ocupar las plazas vacantes. La mencionada situación adquirió un especial y contradictorio matiz político en el caso de los antiguos policías o guardias civiles. Éstos fueron em-

R. I., 1998, n. $^{\circ} 212$ 
pleos que, al igual que otros de la administración pública, habían constituido espacios laborales de los cuales habían sido tradicionalmente discriminados los nativos de la isla durante el gobierno colonial. A pesar de estos antecedentes, algunos antiguos vigilantes del orden público fueron incorporados de facto al cuerpo de policía creado por la administración norteamericana al asumir ésta los destinos del país. Ellos fueron vistos desde la óptica del independentismo post-bélico como usurpadores y representantes del antiguo poder derrocado, pero al mismo tiempo fueron cuestionados en su condición de españoles por parte de los representantes oficiales de la antigua metrópoli: "A algunos tendré que considerarlos como extranjeros como son los antiguos empleados del cuerpo de policía que han seguido en sus puestos después de abandonar España su soberanía en esta Isla"13. Esto, en la práctica, significó para los interesados la privación de su nacionalidad de origen por parte del Estado español y la adopción de una nueva ciudadanía, la cubana, cuyo reconocimiento quizás podía ser admitido con desgana por los cubanos pero, en última instancia, sería cuestionado por los conciudadanos más intransigentes.

\section{LA COLECTIVIDAD ESPAÑOLA TRAS 1898}

En los años inmediatos después de la guerra se sucedieron algunos hechos y desavenencias entre cubanos y españoles, cuya fuerza o importancia está dentro de los límites que podemos considerar como "normales" tras el fin de una contienda. Los atropellos a miembros de la colectividad española, el resentimiento contra las instituciones y el gobierno español, la prohibición de izar la bandera española, e incluso las manifestaciones en contra del monopolio que el español ejercía sobre determinados nichos económicos, son pequeñas manfestaciones del sentimiento popular. Manifestaciones que se canalizaron en estos primeros años hacia los símbolos más destacados de la antigua dominación y que se limitaron a pequeñas acciones. Pero junto a estos ataques al antiguo orden, a veces de carácter xenófobo, de escasa trascendencia y muy acotados en el tiempo, también hay

13 Carta del cónsul de España en Santiago de Cuba Joaquín de Pereyra al Consulado General de La Habana, Santiago de Cuba, 20 de febrero de 1900. AHMAEE. Leg. 2051, Exp. 1900 (Correspondencia Consular, Santiago de Cuba, 1899-1903). 
que destacar las continuas alusiones a la concordia entre españoles y cubanos. La fuerte presencia española en Cuba, que continuaba aumentando con la llegada de nuevos inmigrantes, mantuvo viva la presencia de España en la isla, no sólo desde un punto de vista cultural, sino también étnico y familiar. Un estudio de la composición de la familia cubana en estos años y en las décadas siguientes evidenciaría la presencia y el porcentaje elevado de españoles en ella.

Al margen del hecho de que Cuba fuera un país ocupado por tropas extranjeras y que un instrumento legal reconocido internacionalmente como el Tratado de París fuera el garante de la paz interna, otros factores de peso también pudieron obrar en favor de la concordia, la convivencia pacífica y la colaboración entre cubanos y españoles después del 98. Transcurridos cuatro siglos de ininterrumpida dominación, la sociedad cubana era una sociedad mucho más española que lo que podía representar el $8 \%$ de nativos de la península registrados por el Censo de 1899, con respecto a la población total de $\mathrm{Cuba}^{14}$. Un entramado histórico de vinculaciones económicas y familiares había conformado un espectro social y cultural de definidos matices nacionales, entre los cuales el componente hispano podía identificarse claramente. No puede resultar extraño entonces que, entre los lineamientos elaborados por José Martí, esta realidad hubiera sido reconocida para dejar claramente establecido que el adversario de los cubanos en la guerra no era el español que vivía en el país, sino que la guerra se haría "contra la dependencia de una nación incapaz de gobernar a un pueblo que sólo puede ser feliz sin ella"15.

Es a partir de lineamientos como el anteriormente mencionado, que puede entenderse el hecho de que desde las filas del ejército libertador no partieran consignas dirigidas contra la integridad de los españoles en Cuba. Los problemas derivados de los obstáculos a la independencia que significaba la intervención norteamericana y la desmovilización de las fuerzas cubanas, eran las cuestiones fundamentales que aquejaban la existencia de dicho cuerpo armado en aquellos momentos. El hecho de que el mismo se hubiera mantenido todavía movilizado en las áreas rurales durante algunos meses des-

\footnotetext{
14 Departamento De La GuerRa, Informe sobre el Censo de Cuba. 1899, Washington, Imprenta del Gobierno, 1900, p.106.

15 José MARTí, Obras Completas, La Habana, Editorial Nacional de Cuba, 1963, T. 1, p. 316.
}

R. I., $1998, \mathrm{n}^{\circ} 212$ 
pués de firmada la paz, puede haber obrado como un factor adicional para la neutralización de cualquier acto de violencia contra los españoles que hubiera podido presentarse una vez cesada la guerra. Por otra parte, la influencia y el poder de las élites de nativos de España y sus sucesores favorecidos por el sistema colonial, habían permitido la estructuración de sólidos bloques de poder económico e influencia política en la isla, que continuaron siendo muy importantes para la vida en el país aún despúes de trascendidos los marcos de la dominación colonial. Los grupos oligárquicos de las principales ciudades portuarias de Cuba y sus redes mercantiles, industriales y de servicios, conservaron intacta una parte importante de su poder económico, no obstante la retirada de la estructura de protección que les proporcionaba el estado español y el ingreso en el país de nuevos y poderosos intereses extranjeros ${ }^{16}$.

La intolerancia hacia lo español y el revanchismo no fueron, como ya apuntamos, los rasgos más sobresalientes de las relaciones entre cubanos y españoles una vez cesada la guerra. Varios factores se combinaron para que el natural encono que la sostenida confrontación había causado fuera suavizado. Durante los primeros meses de sustitución de los poderes civil y militar en Cuba es probable que hubieran podido producirse eventuales actos de violencia contra algunos españoles, como los que se registraron en Puerto Rico una vez cesada la dominación española ${ }^{17}$. El marqués de Argüelles, representante de los intereses de España en Cuba por designación expresa del último capitán general de la isla, informó en los primeros meses de 1899 al ministerio de Estado español acerca de la agitación que se había creado por parte de la prensa española en torno a este delicado asunto “...por las demostraciones de rencor, de encubierta hostilidad en unos casos, de venganzas en otros, que se traducen a diario contra todo lo que es español. Justo es consignar que las Autoridades Americanas no ocultan sus simpatías por nosotros, pero se necesita algo más, siquiera para que no sigan los asesinatos (...) y terribles represalias que vienen

\footnotetext{
16 Alejandro García Álvarez, La gran burguesía comercial en Cuba. 1899-1920, La Habana, Editorial de Ciencias Sociales, 1990.

17 Sobre los hechos de esta naturaleza ocurridos en Puerto Rico, ha tratado el historiador Fernando Picó, 1898. La guerra después de la guerra, Río Piedras, Ediciones Huracán, 1987.
} 
denunciadas, ya en quejas directas a esta Delegación, ya en gritos de indignación por la prensa española"18.

\section{REPRESALIAS Y ENTENDIMIENTO}

A pesar de la importancia relativa de los sucesos acaecidos entre ambos grupos tras la guerra, creemos que es necesario conocer lo que pasó y el ambiente vivido como un medio de comprender cómo se llegó a alcanzar la "normalidad", qué elementos contribuyeron a que la paz se alterase y cuáles ayudaron a que el orden y la concordia se restablecieran ${ }^{19}$.

Al entrar en vigor el Tratado de París, el 1 de enero de 1899, quedaron reconocidos específicamente los derechos civiles de los ciudadanos españoles, entre ellos el derecho de los mismos a la propiedad y a ejercer sus actividades profesionales, industriales y comerciales. También el Tratado ofreció a los mismos la opción de conservar la ciudadanía española u optar por la del territorio de residencia $^{20}$, cuestión que en el caso de los nativos de Cuba quedó pendiente de una futura decisión del congreso norteamericano.

Fue precisamente durante los primeros meses de paz cuando se registraron algunos de los hechos que de manera concreta merecieron tales comentarios y los correspondientes informes del cónsul español a su gobierno. Pero dichos informes estuvieron centrados en hechos de importancia menor, como lo fueron algunos intentos de arriar las banderas españolas que en los días festivos solían izarse en los edificios representativos de la colonia española en Cuba, tales como el Centro de Dependientes de La Habana o el Casino Español de Ciego de Ávila. En el primer caso, los hechos se produjeron bajo

\footnotetext{
18 Carta del marqués de Argüelles al presidente del Consejo de Ministros y de Estado de España, La Habana, 30 de marzo de 1899. AHMAEE. Leg. 2950, Exp. E-19 (Sección Ultramar, Cuba, 1898-1900).

19 Para el caso puertorriqueño el estudio de las manifestaciones populares como reacción a la guerra hispanoamericana se ha centrado en el estudio de las "partidas sediciosas". Veáse Fernando PICó [17]. En él se analiza la constitución de las partidas sediciosas como consecuencia del rechazo al régimen económico y social anterior al 98, como una manifestación del conflicto social.

20 "Tratado de paz entre España y los EE.UU., firmado en París en diciembre 10 de 1899", Hortensia PICHARdo, Documentos para la Historia de Cuba (época colonial), La Habana, Editora del Consejo Nacional de Universidades, 1984, pp. 464-465.
} 
la presión ejercida por un grupo de jóvenes de los que solían reunirse en un rincón de cubanía de La Habana conocido como Acera del Louvre y, en el segundo, por una arbitraria decisión del propio alcalde de aquella localidad de la provincia de Puerto Príncipe ${ }^{21}$.

Dentro de éstos quizá el más interesante y que mayor difusión alcanzó en la prensa fue la prohibición de izar la bandera española. El alcalde de La Habana, el Sr. Lacoste, el 5 de octubre de 1899, promulgó un bando por el que se prohibía la utilización de la bandera española en el exterior de los edificios o en cualquier lugar donde se reuniera público, en el término municipal de la Habana, a excepción del consulado general de España, por ser motivo de provocación y desorden. La sanción era de 10 pesos y sólo en caso de reincidencia entraba la Justicia como mediadora en el delito.

Este hecho provocó una fuerte respuesta por parte de la colectividad española en distintos medios como en El Diario de La Marina, a la cual se unieron otros periódicos como El Nuevo País, y Patria, sobre todo, cuando hacía pocos meses que la colonia española había pedido permiso al gobernador general de la isla de Cuba para utilizar la bandera española, lo cual le fue concedido por el general Brooke. Por su parte, el cónsul de España se negó a izar la bandera mientras no se solucionase el agravio, cuyo gesto fue seguido por el cónsul de Gran Bretaña.

Incidentes similares se sucedieron en distintas partes de la isla, sobre todo en las sedes de las asociaciones y centros españoles. Entre ellos la prensa recoge el ocurrido, el 24 de septiembre de 1899 en la Asociación de Dependientes de La Habana, donde un grupo obligó a arriar la bandera española lo cual fue denunciado por el cónsul general de España ante la policía 22 . El Diario de la Marina veía en ello un atropello a la colectividad española y además, una maniobra de los anexionistas para asegurar el mantenimiento de la ocupación norteamericana al provocar un incidente y realizar un acto ilegal aún bajo la ocupación militar norteamericana. Ello demostraría que las autoridades cubanas eran incapaces de mantener el orden y de cum-

\footnotetext{
21 Comunicación del encargado de Negocios de España en Cuba al Ministro de Esta$d o(s / f)$, AHMAEE. Leg. H-1907 (Correspondencia Consular, Habana, 1902-1903).

22 "La bandera española prohibida", Diario de la Marina, 6 de octubre de 1899; "La bandera del Centro de Dependientes", Diario de la Marina, La Habana, 25 de septiembre de 1899.
} 
plir con las obligaciones internacionales propias de un gobierno fuerte y estable ${ }^{23}$.

El incidente es también remarcable por las reacciones que provocó, en muchas de las cuales hallamos otros conceptos más interesantes para nuestro estudio que van más allá de una guerra de banderas y que nos adentra en el campo de las mentalidades. Si la guerra de banderas era una manifestación de las asperezas y resentimientos tras un enfrentamiento armado, también se expusieron otros sentimientos en los que se apelaba a la convivencia entre cubanos y españoles "miembros todos de una gran familia, la familia latina"24. Es ésta una afirmación de gran significado en la época en la que latinos y anglosajones se yuxtaponen como visiones enfrentadas y dicotómicas de ver el mundo, como civilizaciones antagónicas que encarnan valores diferentes y que en esos momentos se traducen a partir del desarrollo tecnológico alcanzado por cada una de ellas, o lo que es lo mismo, a partir de la capacidad de generar y lograr la modernización soñada, lo que les hacía ser una civilización superior y su opuesta inferior. Este concepto de civilización se extrapoló también a la "raza". El término "raza latina" llevaba implícito no tanto un significado étnico como cultural: latinos frente anglosajones y germanos, que en el caso de Cuba no sólo distorsionaba la realidad sino que manifestaba los deseos de una elite, una elite blanca, por presentar a Cuba como un país en el que la "raza latina" era la raíz troncal de su población.

Mención aparte merecen otros acontecimientos en los que la violencia, en distinto grado e intensidad, se dirigió contra determinados individuos de la colectividad española y sus propiedades. A pesar de su existencia, hay que decir que los incidentes de naturaleza violenta, ocurridos entre 1899 y 1905, fueron muy escasos, como, al menos, así lo refleja la correspondencia de los encargados de negocios de España en Cuba. Sin duda, la propia situación de Cuba - un país ocupado por un ejército extranjero, en el que la tranquilidad y el orden debían ser garantizados por el ejército de ocupación-, constituyó un elemento neutralizador de cualquier actividad de violencia que pudiera surgir contra los súbditos españoles. Muy pocos conclu-

23 "El resultado", Diario de la Marina, La Habana, 10 de septiembre de 1899.

24 "La bandera española", Diario de la Marina, La Habana, 29 de septiembre de 1899. 
yeron dramáticamente, es decir, con la muerte de algún ciudadano español. El peligro de muerte apareció más tardíamente cuando un oficial de voluntarios que había abandonado la localidad de Ceiba del Agua desde 1898, reapareció en 1905 para reunirse nuevamente con su esposa e hijos. En aquel momento, una numerosa facción de habitantes del pueblo profiriendo amenazas e insultos, prácticamente sitiaron la casa, y el amenazado tuvo que abandonar el poblado bajo la protección de la guardia rural. Posteriormente, las gestiones del consulado con el sub-secretario de Estado de la república sirvieron para que se prometieran oficialmente garantías para la vida del exoficial amenazado ${ }^{25}$.

Otra naturaleza tuvieron algunos de los hechos sucedidos en localidades cercanas a La Habana y en la región oriental, en los cuales la violencia contra las personas estuvo presente. Uno de ellos tuvo lugar el 10 de junio de 1899, en San Antonio de los Baños, en donde se produjo el asesinato de un súbdito español, con alevosía y premeditación. A raíz de ello, el marqués de Argüelles comentaba el ambiente de revancha que reinaba tras la guerra en los pueblos del interior, en los que el odio y la "hidrofobia" contra el elemento español se había desatado, y se lamentaba de lo inevitable de esta situación que sólo el ejército interventor podría atajar mediante la instalación de destacamentos en estos pueblos. Para el marqués de Argüelles esta actitud de odio e "hidrofobia" además se manifestaba en todos los periódicos, excepto en el Nuevo País ${ }^{26}$.

En el extremo de la isla se producían otros incidentes contra españoles, en esta ocasión el alcalde del poblado de El Cristo, extralimitándose en sus funciones, en 1900, detuvo y expulsó arbitrariamente del pueblo a dos guerrilleros ex-combatientes del ejército español. Éstos apelaron posteriormente a las autoridades de Santiago de Cuba, donde fueron finalmente puestos en libertad por el gobernador civil de aquella ciudad. Un caso similar tuvo lugar en Sagua de Tánamo, localidad donde otro alcalde maltrató y expulsó a un comerciante español que competía en el mercado de la localidad con sus personales intereses mercantiles. El hecho concluyó con la des-

${ }_{25}$ Carta de Andrés López, del consulado de España en Cuba, al ministro de Estado español, 20 de enero de 1905. AHMAEE. Leg. H-1430, Exp. 1905 (Correspondencia Consular, Habana, 1902-1910).

26 AHMAEE, H. 2951 (Sección de Ultramar, Cuba 1898-1900) 
titución del mencionado funcionario de la administración por parte de las autoridades superiores de la provincia ${ }^{27}$.

Una situación con más aristas de complejidad se presentó en otro caso, en que se vieron involucrados los comerciantes españoles Rodón, Soler y Ferret, agente el primero de ellos, de la casa comercial de Santiago de Cuba Brauet y Compañía, en la ciudad de Guantánamo. El incidente se produjo a causa de una acusación infundada realizada por otro español comerciante y rival de aquéllos en los negocios de venta de víveres, sobre una supuesta celebración pública del primer aniversario de la muerte del general Antonio Maceo por parte de los mencionados comerciantes, cuando en realidad se trataba de un brindis por el arribo de Pedro Soler a Cuba, el 8 de diciembre de 1898. Trasmitida la acusación a la prensa local en el momento en que se realizaba en la ciudad una concentración de combatientes del ejército libertador con fines electorales, la mendaz noticia creó una situación de agitación política a la que sólo las autoridades norteamericanas, a petición del cónsul general de España, pudieron dar término dando garantías a los españoles injustamente acusados $^{28}$. Años más tarde, en mayo de 1905 , los hechos se repetían; un súbdito español residente en Guantánamo reclamaba amparo a las autoridades españolas, que le habían desoído en otras ocasiones, por ser de nuevo objeto de atropellos y palizas, sólo por el hecho de ser español ${ }^{29}$.

Este ambiente se avivó en determinadas coyunturas en las que las pasiones políticas se entremezclaron con los recelos hacia los españoles. Así sucedió en 1904, cuando, como consecuencia de la campaña electoral y la lucha entre republicanos y nacionales, varios súbditos españoles residentes en Cienfuegos presentaron denuncias de atropellos ante la policía. Acosados e intimados, los españoles pidieron protección al representante de España tanto para sus vidas como para sus intereses comerciales, que se habían visto afectados al reducirse las ventas. Todo parece indicar que, al menos en estos

27 Carta del cónsul general de España en Santiago de Cuba Joaquín de Pereyra, Santiago de Cuba, 8 de enero de 1900. AHMAEE. Leg. 2051, Exp. 1900 (Correspondencia Consular, Santiago de Cuba, 1899-1903).

28 Comunicaciones del cónsul de España en Santiago de Cuba Joaquín Pereyra, al ministro de Estado de España, 20 de diciembre de 1899 y 8 de enero de 1900. AHMAEE. Leg. 2051, Exp. 20/1900 (Correspondencia Consular, Santiago de Cuba, 1899-1903).

29 AHMAEE, H. 2351 (Serie Política, Cuba, 1904-1912). 
primeros años de siglo, la injerencia, involuntaria o no, de algunos españoles en la política interior de Cuba motivaron sucesos similares al reseñado. Esto era comentado por el cónsul español en La Habana, quien en un informe dejaba traslucir su temor de que se repitieran sucesos parecidos en los períodos electorales y con tensiones políticas $^{30}$.

Otra cara de la moneda la ofrecen las campañas aparecidas en la prensa cubana contra los españoles y España. En diciembre de 1904, ante los sucesivos artículos aparecidos en La Discusión, a cargo de Francisco Hermida, corresponsal en Madrid, contra personas e instituciones españolas, el representante español acreditado en La Habana pidió que se le expulse de España, y solicitó al secretario de Estado y Justicia de Cuba que se paralizasen los artículos ofensivos. En palabras del representante español este periódico, muy barato y por ello de gran difusión, sobre todo entre la población de color, que abominaba de España, era el que llevaba a cabo una campaña más difamatoria contra los españoles, a los que tildaba de "degenerados representantes de la raza latina".

A fin de poner término de forma rápida a este tipo de campañas periodísticas y de impedir que se alentasen otras nuevas se tomaron algunas medidas. Entre ellas hay que mencionar la circular que el gobierno español envió a los cónsules de carrera en La Habana, Cienfuegos y Santiago de Cuba, en diciembre de 1904, en la que se aconsejaba a los españoles y a sus periódicos "la mayor circunspección y prudencia al ocuparse y comentar los actos de los que dirijan los destinos de la nación cubana, y las manifestaciones de los sentimientos de un pueblo", es decir abstenerse de toda intervención en los asuntos cubanos y "de calificar en términos más o menos hostiles, cuanto los gobernantes y el pueblo consideren merecedor de sus aclamaciones y de su cariño", a fin de facilitar la armonía que debe reinar para beneficio de ambas partes y de los intereses económicos de los españoles en Cuba. Por otra parte, se pedía que la prensa española de Cuba no insertara conceptos ni atributos que pudieran herir los sentimientos patrióticos de los cubanos.

La otra medida, tomada en enero de 1905, consistió en aconsejar a los españoles que retirasen del periódico sus anuncios a fin de re-

30 AHMAEE, H. 2351 (Serie Política, Cuba, 1904-1912). 
ducir las ganancias del mencionado periódico. Las consecuencias de esta medida fueron inmediatas, según comenta el representante español, y de los insultos se pasó a un trato cordial y amistoso ${ }^{31}$.

\section{MONOPOLIO Y LUCHAS POR EL TRABAJO}

La complicada situación que se sucedió una vez finalizada la guerra afectó sobre todo la esfera de la política, a causa de la falta de definiciones satisfactorias acerca del problema de la independencia. Durante la misma, amplios sectores de la población de Cuba se mantuvieron en un especial estado de indefensión. Al mismo tiempo, las esferas que podían generar algunos puestos de trabajo se polarizaron en sus preferencias sobre la procedencia nacional del personal que estaban dispuestas a asumir. Mientras que los cubanos eran priorizados en los empleos y trabajos a cargo de la administración pública, los inmigrantes españoles, tanto civiles como ex-militares, eran preferentemente empleados por los empresarios de la misma nacionalidad, los cuales habían constituido tradicionalmente una mayoría en Cuba. Adicionalmente los españoles pudieron contar en su favor con vastas y poderosas redes de conexión y ayuda mutua cuyos principales exponentes institucionales eran los centros regionales de La Habana y los casinos y colonias españoles del interior del país. Fue precisamente debido a estas circunstancias que la defensa del derecho prioritario al trabajo por parte de los nativos cubanos se convirtió en un aspecto de suma importancia en las luchas sociales en los años iniciales del presente siglo, convirtiéndose a la vez en un lastre para la unidad del movimiento obrero. Esto se hace muy evidente en el contenido de los programas y manifiestos dados a conocer por las agrupaciones obreras de la época, tales como la Liga General de los Trabajadores Cubanos, y también a partir de los móviles y planteamientos defendidos por los movimientos huelguísticos que tuvieron lugar tanto durante la intervención norteamericana como una vez inaugurada la república en 1902. En unos y otros siempre estuvo presente como una idea fija la defensa del derecho al trabajo de los cubanos sin distinción de "razas".

31. AHMAEE, H. 2351 (Serie Política, Cuba, 1904-1912).

R. I., $1998, \mathrm{n}^{\circ} 212$ 
Las manifestaciones en contra de los inmigrantes españoles fueron en ocasiones acompañadas de huelgas en las que se reclamaba, junto al aumento del salario, que se prohibiera a los españoles recién llegados ingresar en determinados puestos copados tradicionalmente por ellos ${ }^{32}$. En concreto una de las huelgas más conocidas de este período y que han trascendido más en la historiografía es la huelga de aprendices de 1902 en la que se reclamaba la entrada de cubanos en las fábricas de tabaco como aprendices y la prohibición de que dichos puestos los ocupasen los jóvenes españoles. Era ésta una reivindicación que arrancaba de años atrás y que abarcaba no sólo a los aprendices sino también a otros puestos copados por españoles. En 1899 El Nuevo País, en su edición del 24 de marzo, publicó una carta dirigida al propietario de la fábrica de tabacos Henry Clay, Gustavo Bock, y firmada por Enrique Carballo, Miguel Sánchez y 25 tabaqueros de la fábrica, en la que solicitaban el despido de los capataces y encargados españoles que trabajaban en la empresa de Bock y su sustitución por cubanos ${ }^{33}$.

El esquema laboral que situaba en un extreno al cubano dependiente de los empleos ofrecidos por la administración pública y de la magnitud del presupuesto del Estado cubano, y en el otro a los inmigrantes - españoles sobre todo- en la esfera de la empresa privada agrícola, industrial o de servicios, quedó fijado como un traumatismo en el marco de las relaciones de clase en los inicios del siglo. Dicho conflicto sólo fue cediendo en agudeza pero sin desaparecer completamente, en la medida en que la industria azucarera llegó a recuperar y después superar su nivel de producción anterior a la Guerra de Independencia, y pudieron desarrollarse otros servicios tales como los portuarios y los de transporte ferroviario. De esta manera llegaría a crearse con el tiempo una amplia demanda de fuerza de

32 José RIVERo MuÑIz, "La primera huelga general en Cuba Republicana”, Islas, Vol III, núm. 3, Universidad de Las Villas, 1961. Para el caso de la llamada "huelga de los aprendices", de noviembre de 1902, véase "Carta de la Liga General de los Trabajadores al presidente Estrada Palma", en la obra del Instituto de Historia del Movimiento Comunista y la Revolución Socialista de Cuba, El movimiento obrero cubano. Documentos y Artículos 1865-1925, T. I, La Habana, 1975, pp. 171-182. Véase también el libro de Rafael MARTínEZ ORTIZ, [2], p. 414.

33 El Nuevo País, La Habana, 24 de marzo de 1899. Para el conocimiento de mayores detalles sobre el conflicto de la fábrica Henry Clay \& Bock, se pueden consultar las cartas cruzadas entre Enrique Caraballo y Manuel Sánchez por parte de los obreros, y Gustavo Bock por la patronal, publicadas en La Habana, Imprenta Obispo 135, 1899. 
trabajo, cuyo déficit sólo el incremento de la inmigración estuvo en condiciones de solventar ${ }^{34}$.

A pesar de las protestas justificadas de los cubanos frente al monopolio ejercido por el español en determinados sectores económicos, es también cierto que en estos años algunas de las medidas se tomaron con total impunidad y afectaron a los más débiles del grupo. La prensa se hizo eco de los atropellos que se producían en los trabajos y denunciaron la injusticia de las expulsiones que se realizaban sólo por el hecho de ser españoles, produciéndose en algunas ocasiones la paradoja de que los expulsados si bien eran naturales de España, no se habían inscrito, por distintos motivos, en el Registro de los consulados españoles, por lo que su expulsión era, si cabe, aún más irregular. Los despidos de trabajadores humildes, barrenderos y jornaleros, levantaron protestas en la prensa, cuyos articulistas manifestaban su admiración y repudia tanto por el hecho en sí como por el grupo perjudicado, que en ninguna manera rivalizaba con los oriundos de la isla, así como porque tales acciones gozaban de la aquiescencia del gobierno. Según el Diario de la Marina la medida tomada contra los jornaleros nacidos en España tenía como objetivo dar trabajo a nativos que habían figurado en las filas del ejército libertador. Por otra parte, este diario acusaba al gobierno de ser el responsable del clima creado, ya que lejos de aplacar los ánimos y conciliar posiciones, alentaba y "azuzaba las pasiones de la multitud en esto de negar a los españoles el derecho de ganarse el pan de cada día". De continuar así la situación, comentaba este periódico en 1902 , los españoles expulsados, carentes de recursos para vivir en Cuba y para viajar a España, pedirían al encargado de Negocios que mediase ante el gobierno español para que facilitara la repatriación ${ }^{35}$.

Noticias similares a las publicadas en el Diario de la Marina aparecen en los informes consulares de los representantes españoles.

\footnotetext{
34 Para una valoración cuantitativa de la inmigración española en Cuba en el siglo XX véanse los trabajos de Consuelo NARANJO OROVIO, "Análisis histórico de la emigración española a Cuba, 1900-1959”, Revista de Indias, n 174, Madrid, CSIC, 1984, pp. 507-27; "Trabajo libre e inmigración española a Cuba 1880-1930", Revista de Indias, Vol. LII, n ${ }^{\text {os }}$ 195-196, Madrid, CSIC, 1992, pp. 749-794; "La emigración española a Iberoamérica: análisis cuantitativo", Historia de la emigración española a Iberoamérica, 2 vols., Madrid, Historia 16, 1992, vol. $1^{\circ}$, pp. 177-200.

35 Véanse los artículos "Investigación que se impone" y "Precedente funesto", publicados en el Diario de la Marina, La Habana, 13 de septiembre de 1899 y 25 de julio de 1902 , respectivamente.
} 
En ellos estas actitudes se achacaban a la falta de trabajo en el campo, debido al carácter estacional de la agricultura cubana, y la elevada demanda laboral de los cubanos. Como ya comentamos, las situaciones dudosas de algunos españoles que aún no habían legalizado su situación en Cuba ayudaron a que los abusos pudieran llevarse a cabo con cierta impunidad ${ }^{36}$.

La magnitud del problema provocó que algunas sociedades españolas intentaran ayudar a los españoles que hubieran sido expulsados de los trabajos. Así, en una reunión de una de ellas, celebrada en 1899, en el Casino Español de La Habana, se acordó proponer a todas las sociedades españolas que abrieran un registro de solicitudes de trabajo y demanda de trabajadores ${ }^{37}$. La propuesta fue criticada por algunos periódicos y por la Liga General de Trabajadores que en su Primer Manifiesto y en las bases de su Programa, hacía continuos llamamientos a la igualdad que en el trabajo debían tener cubanos y españoles. La desventaja del cubano por la existencia de redes étnicas que facilitaban la entrada en los trabajos a los españoles en perjuicio de los nativos, provocó la denuncia abierta de la Liga de Trabajadores, que en 1902, en una carta dirigida a Estrada Palma incidía en los privilegios de los que gozaba esta colectividad ${ }^{38}$.

$\mathrm{Al}$ paso de estas acusaciones publicadas en el Diario de la Marina salieron otros periódicos como El Mundo, La Lucha y La Discusión. El análisis de uno de los artículos publicados en uno de estos tres diarios nos puede ilustrar sobre la trascendencia del problema. El Editorial de La Discusión y bajo el título "Sensible, pero necesario", también el 25 de julio de 1902, comentaba con mayor amplitud los hechos exponiendo la grave situación de muchos cubanos que sin trabajo se veían condenados a vagar y mendigar e invitaba al periodista del Diario de la Marina a reflexionar sobre este hecho:

“... reflexione con entera imparcialidad, si era justo, si era político, que mientras los jornaleros cubanos sentían los horrores de la miseria, las cuadrillas de barrenderos de calles fueran formadas por trabajadores inmigrantes sacados de Triscornia para ganar un jornal

\footnotetext{
36. AHMAEE, Leg. H.1907 (Correspondencia Consulados, La Habana, 1902-1903).

37 El Comercio, La Habana, 8 de septiembre de 1899.

38 El movimiento obrero cubano. Documentos y Artículos 1865-1925 [32], p. 194.
} 
que reclamaban para sí, con mayor derecho, los humildes ciudadanos de la República"39.

La escasez de trabajo, el hecho de ser ciudadanos cubanos y el haber prestado "servicios a la Patria" eran motivos sobrados para que la distribución de los trabajos no fuera igual entre cubanos y extranjeros. El articulista resumía la situación de forma clara y rotunda, "La cuestión no puede ser más sencilla. La pobreza es grande y el trabajo es poco".

Al menos durante la primera década del siglo $\mathrm{XX}$, aunque por una parte se alentaba la inmigración, por otra, la realidad, tras largos años de guerra, imponía fuertes restricciones en el reparto del escaso empleo, y, como en otras ocasiones que se sucederían en años posteriores, las crisis económicas, la falta de medios y de trabajo provocaron que la sociedad cerrase sus puertas a lo ajeno y considerase al extranjero perjudicial, rival e incluso usurpador de lo propio.

DE LA PERMANENCIA DE SOLDADOS REGULARES, GUERRILLEROS Y VOLUNTARIOS.

El control militar y político de la situación post-bélica, unido a las características propias de la sociedad cubana, facilitaron la paz entre españoles y cubanos, y una especie de reacomodo del mosaico social de la ex-colonia a las condiciones del protectorado, más que una verdadera integración de los distintos componentes de la misma en una verdadera unidad nacional. La integración entre el sector español y el cubano en el marco de la sociedad insular, resultó así ser tan precaria y formal como la de los ciudadanos negros y blancos entre sí, o la de las clases sociales que luchaban en favor de intereses totalmente opuestos. Todas estas contradicciones pueden ser consideradas como propias de una sociedad de clases que arrastraba como experiencias recientes los pesados lastres del colonialismo y de la esclavitud.

Aunque la contradicción entre españoles y cubanos en aquellos tiempos de tránsito entre la colonia y la república, estuvo dotada de una cierta agudeza, el tiempo transcurrido puso de manifiesto que dicha contradicción tuvo la capacidad de adaptarse al desarrollo de la realidad neocolonial. Esto se reflejó de manera muy particular en

39 "Sensible, pero necesario", La Discusión, La Habana, 25 de julio de 1902

R. I., $1998, \mathrm{n}^{\circ} 212$ 
el caso de los soldados que combatieron en defensa del dominio español sobre la mayor de las Antillas. Para los soldados españoles, Cuba había sido además de un destino militar y un espacio burocrático, un atractivo polo para la emigración y para un supuesto enriquecimiento rápido. La medida en que el mito del indiano tomó forma en la mentalidad del español de la segunda mitad del siglo XIX y principios del XX, está todavía por estudiar. A diferencia de esto, el problema de la repatriación de los combatientes españoles ha sido estudiado por distintos autores desde diferentes ópticas ${ }^{40}$, especialmente en el caso de los llamados quintos, es decir, de los soldados reclutados y enviados al campo de batalla sin la preparación y aclimatación necesarias para el combate. Sin embargo, en Cuba permaneció un número indeterminado de soldados que combatieron en favor de España formando parte de sus tropas, sobre los cuales poco se sabe. La integración de estos ex-combatientes a la sociedad cubana después del 98 se verificó aparentemente sin dificultades mayores, a partir de la existencia y desarrollo de vínculos e intereses de índole variada, como pueden haber sido los de carácter laboral, familiar o, simplemente, sociales. Los fondos del Archivo Histórico del Ministerio de Asuntos Exteriores, en Madrid, contienen un número importante de las comunicaciones elevadas por los cónsules españoles a los ministerios de Guerra y Marina, en solicitud de pensiones o ajustes a las mismas, formuladas individualmente, o por grupos de combatientes de la guerra de Cuba, así como también por algunos de sus familiares. La totalidad de dichos expedientes, incluyendo los relacionados con las pensiones concedidas o denegadas, deben obrar en los archivos de aquellas otras dependencias españolas, en espera de la paciencia de algún historiador interesado. Su consulta permitiría no sólo el conocimiento del número total y calidad de los pensionados del gobierno español en Cuba después del 98, sino también la cuantificación del monto total que dicha transferencia de numerario significó. No obstante, la documentación existente en este archivo es suficiente para la formación de una muestra

40 M. MORENo [8]; Jordi MALUQUER DE MOTES, Nación e inmigración: los españoles en Cuba (ss. XIX y XX). Oviedo, Ediciones Jucar, 1992, y Rafael NuÑEZ FlorENCIO, "Los otros españoles que fueron a Cuba: el drama de los repatriados", C. NARANJO, M.A. PUIGSAMPER, L.M. García (eds.), La nación soñada: Cuba, Puerto Rico y Filipinas, [2], pp. 597-619. 
que arroje ciertos detalles sobre el comportamiento de algunos aspectos cuantitativos de dicho fenómeno.

En el caso de la documentación utilizada para lograr un acercamiento a este asunto, se trata de reclamaciones de pensiones que fueron en muy pocos casos concedidas o ajustadas, resultanto por lo tanto, desestimadas en la mayor parte de los mismos. Las causas utilizadas como fundamento para estas conclusiones se sustentaron en argumentos de distinta naturaleza, entre los cuales se pueden mencionar la extinción del tiempo establecido para la reclamación, el agotamiento de los fondos destinados a tal fin, el no haberse solicitado la repatriación antes del término fijado para ello, el encontrarse el interesado en Cuba sin haber reclamado la nacionalidad española, y otros argumentos más, entre los que se reiteran sobre todo, los relacionados con la permanencia de los reclamantes en Cuba y la conservación o no de la nacionalidad española.

La muestra empleada para lograr esta aproximación al conocimiento de la permanencia de los combatientes del ejército colonial español en la Cuba después del 98, consta de 336 casos de reclamación o ajuste de pensiones, formuladas sobre todo entre 1899 y 1905. A partir de los mismos, aunque no resulta posible conocer el monto total de los ex-combatientes del ejército español que permanecieron en Cuba después del armisticio, sin embargo puede lograrse una idea de la composición de dicha masa de ex-combatientes, desde el punto de vista de su categoría militar (regulares, irregulares o guerrilleros y voluntarios), sus grados, y también la valoración de otras cuestiones, tales como las proporciones de viudas, hijos, y otros aspectos de interés.

La composición de la muestra, desde el punto de vista del tipo de las tropas de las cuales formaron parte los combatientes, arrojó como resultado que la mayor parte de los soldados había pertenecido a las tropas regulares del ejército español, siendo las proporciones de guerrilleros (irregulares) y de voluntarios mucho menores. Bajo el rubro de "Otros" aparecen también los militares que prestaban servicios en actividades muy específicas, tales como marinos, fogoneros, músicos, personal sanitario, prácticos, etc. El siguiente cuadro muestra dicha distribución. 
PROPORCIONES DE SOLDADOS REGULARES, GUERRILLEROS, VOLUNTARIOS Y OTROS AL SERVICIO DEL EJÉRCITO ESPAÑOL EN LA GUERRA DE CUBA.

\begin{tabular}{l|c}
\hline TIPO DE SOLDADO & $\%$ \\
\hline Tropas regulares & 59,82 \\
Tropas irregulares (guerrilla) & 15,18 \\
Voluntarios & 17,86 \\
Otros & 7,14 \\
\hline
\end{tabular}

Fuente: Elaboración propia. AHMAEE, Correspondencia Consular de Cuba, (1898-1905)

A partir de la totalidad de los casos, se ha podido determinar que el $81,90 \%$ de las reclamaciones corresponden a soldados que permanecieron vivos en el territorio nacional cubano, mientras que el $11,50 \%$ corresponde a viudas de combatientes muertos y, solamente el $6,60 \%$ tiene que ver con huérfanos de la guerra que reclamaban pensiones. Del total de viudas, el 74,36\% lo eran de soldados regulares, mientras que las de guerrilleros o de voluntarios lo eran del $12,82 \%$ para cada caso. Similar situación se observa en el caso de los huérfanos, sólo que el total $(100 \%)$ de las mismas corresponde a huérfanos de combatientes del ejército regular.

Con relación a los grados de los combatientes del bando español que quedaron residiendo en Cuba incluyendo los casos de los correspondientes a pensionados por fallecimiento, según la muestra tomada, el $71,43 \%$ eran simplemente soldados para un número total de 240 , mientras que las clases y oficiales agrupaban un $28,51 \%$, es decir, un total de 96 militares con grados. La distribución de la muestra arroja el resultado que a continuación se expone.

DISTRIBUCIÓN DE LA MUESTRA DE SOLDADOS SEGÚN SU GRADACIÓN MILITAR.

\begin{tabular}{lc}
\hline GRADACIÓN & NÚMERO \\
\hline Soldados & 240 \\
Cabos & 13 \\
Sargentos & 6 \\
Tenientes & 36 \\
Capitanes & 32
\end{tabular}




\begin{tabular}{lr} 
Comandantes & 6 \\
Teniente-Coronel & 3 \\
\cline { 2 - 2 } Total & $\mathbf{3 3 6}$
\end{tabular}

Fuente: AHMAEE, Correspondencia Consular de Cuba (1898-1905).

Entre las peticiones hechas con reiteración por los combatientes residentes en Cuba, se mantuvieron como aspiraciones totalmente opuestas y en diferentes proporciones, las peticiones de repatriación, y las solicitudes de permiso para permanecer en el territorio "extranjero" de la ex-colonia. En este sentido, se ha podido cuantificar un $4,36 \%$ de solicitudes de regreso a la patria, realizadas generalmente fuera de las fechas establecidas para ello, y un $10,55 \%$ de solicitudes de permiso para continuar residiendo en Cuba, alegando diferentes causas. Esto permite conocer que había una permanencia previa, autorizada o no, de los soldados en el territorio de la isla. A partir del conocimiento de estos detalles, cabe la hipótesis de que muchos de los permisos para residir en el exterior pueden haber sido concedidos a los interesados por otras vías, o con anterioridad.

El problema de la ubicación de los ex-combatientes españoles en el territorio cubano puede ofrecer cierta distorsión en la muestra utilizada, a causa de que la mayor parte de las solicitudes formuladas por escrito, con todos sus datos, corresponden sobre todo al consulado español en Santiago de Cuba, en cuyas oficinas se tramitaron además los casos de la provincia de Puerto Príncipe. Un grupo importante de reclamaciones no especifica el lugar de residencia del reclamante (el 40,77\%). Sin embargo, una parte mayor, el 47,92\%, señala como lugar habitual de residencia la ciudad de Santiago de Cuba, el 4,76\% Puerto Príncipe, el 3,87\% Santa Clara y sólo el 2,68 la provincia de La Habana, no apareciendo en los consulados de Cienfuegos y en el general de La Habana, una información suficiente sobre este asunto, en correspondencia con la importancia demográfica de estas zonas del país.

La eventualidad de permanecer en Cuba para convertirse de hecho en un inmigrante, fue una opción asumida por quienes estuvieron ligados a la ex-colonia por algún tipo de vínculo, o por aquéllos que simplemente confiaban en el futuro desenvolvimiento de Cuba bajo el control de Estados Unidos. Las posibilidades de realizar alguna actividad económica u obtener empleo deben haber bastado en 
muchos casos para la toma de semejante decisión. En opinión del Comisionado Especial de los Estados Unidos, designado para Cuba y Puerto Rico, "Muchos soldados españoles desean permanecer en la Isla. Ellos han creado lazos en Cuba - algunos se han casado y tienen familias aquí-. Estos hombres han venido a suplicar se les ayude a encontrar empleo de alguna clase, tanto como custodios en las minas, como en las plantaciones. Como regla, ellos pueden ser fieles e industriosos trabajadores" 41 .

A pesar de las manifestaciones de inconformidad que tuvieron lugar sobre todo en La Habana durante los años de la intervención norteamericana y los primeros de la república, con respecto a la escasez de empleos y las preferencias en favor de la contratación de españoles en el sector tabacalero, la escasez de fuerza de trabajo fue un problema de singular agudeza visto a escala de todo el país. El desempleo registrado en La Habana a causa de una concentración desproporcionada de fuerza de trabajo en la capital tuvo su contrapartida en la escasez de brazos que se observaba en muchas de las restantes provincias del país. Dispersada la población campesina a causa de la reconcentración decretada por el general Weyler durante la guerra, e incorporados masivamente los hombres a las operaciones militares de uno u otro bando, la paz encontró entre los sobrevivientes de la guerra en las zonas rurales, pocas posibilidades de satisfacer los requerimientos de fuerza de trabajo que demandaba la reconstrucción de la industria azucarera y la rehabilitación de la minería. Aunque las fuerzas del ejército libertador podían ser vistas por los hacendados como una potencial fuente de braceros, una evaluación realizada por los norteamericanos sobre la situación de la fuerza laboral en Cuba a partir del cese de la guerra, reconoció con claridad dicho desbalance ${ }^{42}$. Por ello es que el principal problema del déficit laboral estuvo desde un principio en la distribución territorial de la fuerza de trabajo. Para intentar su redistribución se hizo nece-

${ }_{41}$ "Many Spanish soldiers desire to remain in the island. They have formed alliances in Cuba -some of them have married and have families there. These men have come before your conmissioner and entreated him to aid in finding them employment of some kind, either as civil guards, in the mines, or on the plantations. As a rule, they made industrious and faithful laborers", Robert PORTER, Report on the Comercial and Industrial Condition of the Island of Cuba, Washington, Government Printing Office, 1898, pp. 13.

42 Ibidem, pp. 12-15. 
sario destinar recursos para el avituallamiento y el transporte de los braceros desde los lugares en que se encontraban ociosos hasta los destinos laborales más urgidos de fuerza de trabajo, ya que los potenciales trabajadores carecían en aquellos momentos de los recursos necesarios para afrontar dicho traslado. Según el informe mencionado anteriormente, los destinos fundamentales fueron los nuevos centrales azucareros cuya construcción se había iniciado en la provincia más oriental del país una vez terminada la contienda, y las minas que operaban algunas empresas norteamericanas en los alrededores de Santiago de Cuba.

La rehabilitación y crecimiento de la industria azucarera en los años de la intervención norteamericana y los primeros cuatro años de administración republicana, permitieron gradualmente la ampliación del rango exportador del país en sus rubros fundamentales. En muy poco tiempo se logró la construcción de nuevas vías férreas que unieron la zonas central y oriental con el occidente, integrando así los transportes y las comunicaciones interiores del país en un sistema más amplio y eficiente ${ }^{43}$. Para asumir el reto planteado por el desarrollo de la infraestructura y la economía ya no bastaron los trabajadores nativos, ni los soldados españoles que habían permanecido en Cuba. El abastecimiento de fuerza de trabajo volvió a descansar, como en los siglos XVIII y XIX, en la mano de obra importada, en inmigrantes que sin interrupción continuaron llegando de España y también en braceros procedentes de las islas del Caribe que clandestinamente solían arribar a las playas de la región oriental. A partir de estas circunstancias, la sociedad cubana debió afrontar posteriormente un doloroso proceso social y político encaminado a la superación de los obstáculos que dificultaban su integración nacional. En el mismo, los hombres que de algún modo habían combatido en defensa del domino colonial español sobre Cuba fueron asimilados por la nueva realidad neocolonial, acogiéndose finalmente al espacio que les asignó la república.

43 Oscar ZANETTI y Alejandro GARCíA, Caminos para el azúcar, La Habana, Editorial de Ciencias Sociales, 1987, capítulo 2, segunda parte.

R. I., $1998, \mathrm{n}^{\circ} 212$ 
Once a consensus was reached in the system of comercial and political relations between Spain and Cuba, the readjustment in the interaction between Cubans and Spaniards was easier, as the situation of open war turned into another of peaceful coexistence guaranteed by the jural framework of the new republic, strengthened by the rise of Spanish imigration, and sustained by the enormous infuence of the Hispano-Cuban cultural tradition. 